\title{
Disease Profile and Outcome of Newborn Admitted to Neonatology Unit of BPKIHS
}

\author{
Piush Kanodia, Sunil Kumar Yadav, Nisha Keshary Bhatta, Rupa Rajbhandari Singh \\ Neonatology Division, Department of Pediatrics and Adolescent Medicine, BP Koirala Institute of Health \\ Sciences (BPKIHS), Dharan, Nepal
}

\section{Correspondence \\ Dr Piush Kanodia}

DM Neonatology Resident

Department of Pediatrics

BPKIHS, Dharan, Nepal

E-mail:

Piushkanodia@yahoo.com

Mobile No: 9858024990

\section{DOI:}

http://dx.doi.org/10.3126/

jemsn.v11i3.14059

\begin{abstract}
Background \& Objectives: Neonatal period is a vulnerable time in which the newborn has to adapt to a totally new environment and is susceptible to many problems, which may even be life threatening. Every year, millions of neonates are born and a large proportion of them are admitted to the neonatal intensive care unit (NICU) for various indications. It is found that neonatal mortality rate is decreasing in Nepal but at a slower pace than infant and child mortality. In order to improve neonatal outcome, it is crucial to identify the areas where health care can be improved. Therefore, this study was conducted to identify the clinical profile, pattern of diseases and common causes of mortality and morbidity in neonates admitted to neonatology unit. Materials \& Methods: A retrospective study was conducted at neonatology unit of BPKIHS, from January 2014 to December 2014. A total of 1009 neonates (both inborn and out-born) were admitted to neonatology division during the study period. Data was collected from the hospital record section. Ethical clearance was taken from the institutional ethical committee before the initiation of the study. Data was entered and descriptive analysis was done by using SPSS 20.0. Results: Total of 1009 neonates were admitted in neonatology unit. Among them, 349(34.5\%) cases were admitted due neonatal sepsis, $236(23.3 \%)$ due to prematurity and $233(23.1 \%)$ with birth asphyxia. Among birth asphyxia, 102(43.7\%) were in HIE III, 34.3\% and $21.8 \%$ in HIE II and HIE I, respectively. The overall mortality was 47 (4.7\%) during hospital stay. Conclusion: Sepsis, prematurity and birth asphyxia were major causes for admission in NICU. All these etiologies are preventable up to some extent and, if detected earlier, can be effectively treated in order to reduce morbidity and mortality.

Key words: Birth asphyxia; Neonatal mortality; Prematurity; Sepsis.
\end{abstract}

Citation: Kanodia P, Yadav SK, Bhatta NK, Singh RR. Disease profile and outcome of newborn admitted to neonatology unit of BPKIHS. JCMS Nepal. 2015;11(3):20-24.

\section{INTRODUCTION}

Neonatal period (0-28 days of life) is a very vulnerable period of life and most diseases are preventable at neonatal period. ${ }^{1}$ According to the WHO, out of 130 million babies born every year 4 million newborn die during neonatal period. ${ }^{2}$ The neonatal disease pattern is a sensitive indicator of availability, utilization and effectiveness of mother and child health services in the community. The Nepal Demographic and Health Survey of 2011 found neonatal mortality rate of $33 / 1000$ live births. $^{3}$
The pattern of neonatal disease changes from time to time even at the same place. ${ }^{4}$ According to a study done in Nepal, asphyxia is the leading cause of hospital admission (22\%) followed by prematurity (20\%) and sepsis (17\%) with mortality due to these three causes being $7 \%, 3 \%$ and $5 \%$ respectively. ${ }^{5}$ Sepsis, jaundice, birth asphyxia and pneumonia are the leading causes of mortality and morbidity and can be prevented by good obstetric and perinatal management. ${ }^{6}$

The objective of the study was to know the disease pattern of newborn in Nepal for better management 
and outcome.

\section{MATERIALS AND METHODS}

This was a retrospective study conducted at the Department of Pediatrics and Adolescent Medicine, BPKIHS Dharan, Nepal. Retrospective data of 2014 (January 2014 to December 2014) were recorded from medical record section of hospital. A total of 1009 neonates (both inborn and out-born) were admitted during this period and were included in the study. Neonatology division of BPKIHS has facilities of mechanical ventilation, arterial blood gas monitoring, central oxygen line, warmers, phototherapy, Bubble CPAP and multichannel patient monitor etc, which are needed for care of sick neonates. Data on age at admission, gender, gestational age, birth weight, initial presenting symptoms at admission, final diagnosis and outcome in regards to whether the newborn was discharged after completion of treatment, discharged on request, left against medical advice, referred or expired were collected. Cases whose data were not available were excluded. Diagnosis was mainly clinical with specific laboratory or radiological findings. Sepsis and meningitis were diagnosed on clinical grounds along with $\mathrm{C}$-reactive protein (CRP), complete blood count (CBC), positive blood culture and cerebrospinal fluid (CSF) examination. Congenital heart disease was confirmed by Echocardiography.

Birth weight less than 2500 grams was defined as low birth weight ${ }^{7}$ and any live born baby before 37 completed weeks was defined as premature. ${ }^{8}$ Neonatal sepsis was classified as suspected and culture proven sepsis on the basis of clinical profile, septic screen and blood culture. ${ }^{9}$ Diagnosis of perinatal asphyxia was based on the criteria set by the National Neonatology Forum of India and World Health Organization. ${ }^{10}$ APGAR score at one minute of 0 to 3 and 4 to 7 signifies severe and moderate birth asphyxia respectively. Hypoxic ischemic encephalopathy was classified on the basis of Sarnat and Sarnat staging. ${ }^{11}$ Ethical clearance was taken from the institutional ethical committee before the initiation of the study. Data was entered and analyzed using SPSS 20.0.

\section{RESULT}

During the period of study, total of 1009 neonates were admitted to the Neonatology division. A total of $415(41.1 \%)$ babies were inborn and 594(58.8\%) were outborn. Maximum numbers of babies were admitted through the emergency room or outpatient department. There were 679 males and 330 females. Majority of the babies $(n=715 ; 70.8 \%)$ were term, 294 (29.1\%) were preterm. Number of babies admitted on the first day of life was 561(55.5\%); whereas 390 babies (38.6\%) were admitted between second to seventh days of life. Similarly, 58 newborn $(5.7 \%)$ were admitted on $>7^{\text {th }}$ day of life.

The commonest indication for admission was neonatal sepsis $(n=349 ; 34.5 \%)$ followed by prematurity $(\mathrm{n}=236 ; 23.3 \%)$ and perinatal asphyxia $(\mathrm{n}=233 ; 23.1 \%)$ (Table 1 and 2$)$.

Table 1. Distribution of study subjects

\begin{tabular}{|c|c|c|c|}
\hline \multicolumn{2}{|c|}{ Diseases } & $\begin{array}{c}\text { Number } \\
(\%)\end{array}$ & Total \\
\hline \multirow{3}{*}{$\begin{array}{l}\text { Early onset } \\
\text { sepsis }\end{array}$} & Pneumonia & $\begin{array}{c}42 \\
(21.6 \%)\end{array}$ & \multirow{3}{*}{$\begin{array}{c}194 \\
(19.2 \%)\end{array}$} \\
\hline & Septicemia & $\begin{array}{c}124 \\
(63.9 \%)\end{array}$ & \\
\hline & Meningitis & $\begin{array}{c}28 \\
(14.4 \%)\end{array}$ & \\
\hline \multirow{3}{*}{$\begin{array}{l}\text { Late onset } \\
\text { Sepsis }\end{array}$} & Pneumonia & $\begin{array}{c}15 \\
(9.6 \%)\end{array}$ & \multirow{3}{*}{$\begin{array}{c}155 \\
(15.3 \%)\end{array}$} \\
\hline & Septicemia & $\begin{array}{c}74 \\
(47.7 \%)\end{array}$ & \\
\hline & Meningitis & $\begin{array}{c}66 \\
(42.5 \%)\end{array}$ & \\
\hline \multicolumn{2}{|l|}{ Prematurity } & $\begin{array}{c}236 \\
(23.3 \%)\end{array}$ & $\begin{array}{c}236 \\
(23.3 \%)\end{array}$ \\
\hline \multirow{3}{*}{$\begin{array}{l}\text { Birth } \\
\text { asphyxia }\end{array}$} & HIE I & $\begin{array}{c}51 \\
(21.8 \%)\end{array}$ & \multirow{3}{*}{$\begin{array}{c}233 \\
(23.1 \%)\end{array}$} \\
\hline & HIE II & $\begin{array}{c}80 \\
(34.3 \%)\end{array}$ & \\
\hline & HIE III & $\begin{array}{c}102 \\
(43.7 \%)\end{array}$ & \\
\hline \multicolumn{2}{|c|}{$\begin{array}{l}\text { Meconium aspiration } \\
\text { syndrome }\end{array}$} & $\begin{array}{c}66 \\
(6.5 \%)\end{array}$ & $\begin{array}{c}66 \\
(6.5 \%)\end{array}$ \\
\hline \multicolumn{2}{|c|}{ Neonatal jaundice } & $\begin{array}{c}60 \\
(5.9 \%)\end{array}$ & $\begin{array}{c}60 \\
(5.9 \%)\end{array}$ \\
\hline \multicolumn{2}{|c|}{$\begin{array}{l}\text { Transient tachypnea of } \\
\text { newborn }\end{array}$} & $\begin{array}{c}24 \\
(2.3 \%)\end{array}$ & $\begin{array}{c}24 \\
(2.3 \%)\end{array}$ \\
\hline \multicolumn{2}{|c|}{$\begin{array}{l}\text { Congenital anomalies, } \\
\text { birth defects and } \\
\text { syndromes }\end{array}$} & & $\begin{array}{c}41 \\
(4.06 \%)\end{array}$ \\
\hline \multicolumn{2}{|l|}{ Total } & & $\begin{array}{c}1009 \\
(100 \%)\end{array}$ \\
\hline
\end{tabular}


Table 2. Congenital anomalies, birth defects and syndromes

\begin{tabular}{|ll|}
$\begin{array}{l}\text { Congenital anomalies, birth } \\
\text { defects and syndromes }\end{array}$ & Number (\%) \\
\hline Duodenal atresia & $2(0.1 \%)$ \\
\hline Congenital heart disease & $14(1.3 \%)$ \\
\hline VACTERL anomalies & $4(0.39 \%)$ \\
\hline Tracheo-esophageal fistula & $7(0.69 \%)$ \\
\hline Congenital hydrocephalus & $4(0.39 \%)$ \\
\hline Choanal atresia & $1(0.09 \%)$ \\
\hline Congenital mesenteric cyst & $1(0.09 \%)$ \\
\hline Situs inversus & $1(0.09 \%)$ \\
\hline Brachial plexus injury & $1(0.09 \%)$ \\
\hline Down syndrome & $2(0.1 \%)$ \\
\hline Goldenhar syndrome & $1(0.09 \%)$ \\
\hline Cleft lip and palate & $2(0.1 \%)$ \\
\hline Macrosomia & $1(0.09 \%)$ \\
\hline Total & $\mathbf{4 1 ( 4 . 0 6 \% )}$ \\
\hline
\end{tabular}

Among 1009 newborn, 68 babies (6.7\%) required mechanical ventilation, $110(10.9 \%)$ were on bubble CPAP and 27(2.6\%) went for double volume exchange transfusion (Table 3).

Positive blood cultures were identified from 166 (16.4\%) newborn babies. Among 1009 newborn, $59.03 \%, 7.22 \%$ and $19.27 \%$ had Staphylococcus aureus, Klebsiella and Acinetobacter respectively (Table 4). Among 1009 newborns, 486(48\%) were discharged within 2-5 days of admission. A total of $264(26 \%)$ stayed for six to 10 days, $102(10 \%)$ each for 10 to 14 and more than 14 days and 57 $(6 \%)$ for less than a day. 814 babies $(80.6 \%)$ were discharged after improvement, 107(10.6\%) left

Table 3. Intervention performed in study subjects

\begin{tabular}{ll}
\hline Procedures & $\mathbf{n}=\mathbf{1 0 0 9}$ \\
\hline Bubble CPAP & $110(10.9 \%)$ \\
\hline $\begin{array}{l}\text { Double volume exchange } \\
\text { transfusion }\end{array}$ & $27(2.6 \%)$ \\
\hline Mechanical ventilation & $68(6.7 \%)$ \\
\hline Blood transfusion & $102(10.1 \%)$ \\
\hline Phototherapy & $78(7.7 \%)$ \\
\hline Laparotomy & $3(0.3 \%)$ \\
\hline Lumbar puncture & $205(20.3 \%)$ \\
\hline Procedure not required & $416(41.22 \%)$ \\
\hline Total & $\mathbf{1 0 0 9}(\mathbf{1 0 0} \%)$ \\
\hline
\end{tabular}

Table 4. Distribution of organisms grown on blood culture

\begin{tabular}{ll} 
Organisms & $\mathbf{n}=\mathbf{1 6 6}$ \\
$\begin{array}{l}\text { Methicillin resistant } \\
\text { Staphylococcus aureus }\end{array}$ & $98(59.03 \%)$ \\
\hline Klebsiella pneumoniae & $12(7.22 \%)$ \\
\hline Acinetobacter species & $32(19.27 \%)$ \\
\hline Citrobacter koseri & $2(1.2 \%)$ \\
\hline Enterococcus species & $14(8.43 \%)$ \\
\hline Coagulase negative staphylococcus & $8(4.81 \%)$
\end{tabular}

Table 5. Outcome distribution

\begin{tabular}{|ll} 
Outcome & $\mathbf{n}=\mathbf{1 0 0 9}$ \\
\hline Improved & $814(80.6 \%)$ \\
\hline LAMA & $107(10.6 \%)$ \\
\hline Mortality & $47(4.6 \%)$ \\
\hline Referred & $26(2.5 \%)$ \\
\hline Discharge against advices & $15(1.5 \%)$ \\
\hline
\end{tabular}

against medical advice, 26(2.5\%) babies were referred to higher centers for surgical interventions and there were 47 (4.6\%) mortalities. Commonest causes for mortality were hyaline membrane disease $12(25 \%)$ and hypoxic ischemic encephalopathy $10(20 \%)$ and Sepsis 10 (20\%) (Table 5).

\section{DISCUSSION}

BPKIHS is a tertiary-care and teaching hospital at Eastern region of Nepal. Many neonates are admitted in later stage of the disease or complicated by their illnesses.

Total 1009 newborns were admitted in neonatology division during study period. Males were predominant in our study, which was similar to other studies. ${ }^{12,13}$ Males get more attention on part of caregivers and are brought to the hospital for seeking health services. In the present study, most of our admissions $(55.5 \%)$ occurred during the first 24 hours of life. This was similar to a study done in Nepal, which found the $44.5 \%$ of admissions occurred during the first 24 hours of $l i f \mathrm{e}^{14}$. This emphasizes the fact that most of the neonatal problems present within the first day of life, during which early detection and intervention is crucial. 
Sepsis accounted for about one-third cases requiring admission in our NICU. Jan et al. also reported a high incidence $(41.3 \%)$ of neonatal sepsis. ${ }^{12}$ However, lower incidences (6.4-10.5\%) were reported by other authors in their studies. ${ }^{13,15}$ Early and late onset sepsis were accounted almost equal in our study. Risk factors for neonatal sepsis during antenatal, intrapartum and postnatal period are equally important and should be taken into consideration for its prevention.

Prematurity was the next common cause (23.3\%) for admission, which was similar to the study reported from South Africa. ${ }^{16}$ In contrast, much higher incidence (34.6- 48.2\%) has been reported from other neighboring countries. ${ }^{13,17}$ Preterm neonates really require very close attention and advanced care because of their inherent problems and complications. Preventive aspects should be taken into consideration for the betterment of newborn.

Birth asphyxia (23.1\%) accounted for the third most common cause of admissions to our unit. The incidence is almost similar to the study conducted by Butt et al. ${ }^{18}$ and much lower than reported from South Africa. ${ }^{19}$ Thus occurrence of high incidence of severe birth asphyxia indicate that, the level of neonatal care existing in our health sector especially in the community is not appropriate. So adequate attention is to be paid in training of health workers that can effectively reduce the incidence as well as its severity and decrease the load of NICU admissions at tertiary care level.

Neonatal hyperbilirubinemia is the common cause of admissions in NICU and it accounts for $5.9 \%$ of admissions. Much higher incidences (36.2-54\%) have been reported in other studies. ${ }^{18,20,21}$ Cases of neonatal hyperbilirubinemia were mainly admitted for exchange transfusion and phototherapy. However, these could have been curtailed by early detection, bilirubin monitoring and effective phototherapy. Congenital anomalies like jejunal atresia, anal atresia, and tracheo-esephageal fistula required surgical interventions. Rests were minor malformations and had accompanying features with some other illnesses requiring therapy. Methicillin resistant Staphylococcus aureus was detected in $59.03 \%$ of cases followed by Pseudomonas species, Klebsiella pneumonia, Enterococcus and
Acinetobacter. Other authors reported Staphylococcus aureus, Coagulase Negative Staphylococcus (CoNS) and Klebsiella pneumoniae as the three predominant pathogens in their studies. However, they did not mention regarding methicillin resistance in Staphylococcal isolates. ${ }^{22,23}$ Overall mortality observed was $4.6 \%$. Mortality is low in our setup but in contrast, rate of LAMA (leave against medical advice) is high. Other studies have reported higher mortality rates $(25.8-34 \%)$ but Jan et al. ${ }^{26}$ found much lower mortality $(8.3 \%)$ in their audit report. ${ }^{24,25}$ The mortality depends upon the stage of the disease and facilities available in a particular NICU. Moreover, attempt should be made to keep it as low as possible.

\section{CONCLUSION}

Infection was the leading cause of admission into the neonatal care unit, followed by prematurity and birth asphyxia. Neonatal sepsis is the leading cause of morbidity and mortality in our part of world. This study was done to know the disease pattern among newborn which is important for good neonatal care and development of preventive strategies. Majority of the admissions occurred within the first 24 hours of life. Therefore to improve neonatal outcome, it is imperative to be vigilant especially during the first 24 hours of life. Progress is possible, but only if we manage to prevent or detect and treat problems as early as possible, which can be achieved by public awareness, training of manpower and procurement of necessary equipments and also by improving antenatal care of pregnant women, timely interventions of high risk pregnancies.

\section{REFERENCES}

1. Chaudhry IJ, Chaudhry NA, Hussain R, Munir M, Tayyab M. Neonatal septicemia. Pak Postgrad Med J. 2003;14:1822.

2. Zupan J, Aahman E. Perinatal mortality for the year 2000 : estimates developed by WHO. Geneva: World Health Organization; 2005.

3. Ministry of Health and Population (MOHP) [Nepal], New ERA, ICF International Inc. Nepal Demographic and Health Survey 2011. Kathmandu, Nepal: Ministry of Health and Population, New ERA, ICF International; 2012.

4. Aurangzeb B, Hameed A. Neonatal sepsis in hospital born babies: bacterial isolates and antibiotic susceptibility patterns. J Coll Physicians Surg Pak. 2003;13(11):629-32. PMID:14700488.

5. Gurubacharya SM, Gurubacharya RL. An overview of neonatal admissions at College of Medical Sciences. J 
Nepal Paediatr Soc. 2007;27(2):73-4.

7. Khinchi YR, Kumar A, Yadav S. Profile of neonatal sepsis. J Coll Med Sci Nepal. 2010;6(2):1-6. DOI:10.3126/ jcmsn.v6i2.3609. UNICEF, World Health Organization. Low Birth weight: Country, regional and global estimates [Internet]. UNICEF, WHO; 2004.

8. World Health Organisation. Fact sheet 2014 [Internet]. Geneva: WHO; 2014 [cited 2014 Nov 10]. Available from: www.who.int/en.

9. Polin RA. Management of neonates with suspected or proven early-onset bacterial sepsis. Pediatrics. 2012;129 (5):1006-15.

DOI:10.1542/peds.2012-0541; PMID:22547779.

10. National Neonatology Forum of India. Teaching Aids on Newborn Care: Post Asphyxia Management [Internet]. New Delhi: National Neonatology Forum of India; [cited 2014 Nov 10].

11. Sarnat HB, Sarnat MS. Neonatal encephalopathy following fetal distress: a clinical and electroencephalographic study. Arch Neurol. 1976; 33(10):696-705. DOI: 10.1001/ archneur.1976.00500100030012.

12. Rahim F, Mohammad AJ, Iqbal H. Patterns and outcome of admissions to neonatal unit of Khyber Teaching Hospital, Peshawar. Pak J Med Sci. 2007;23:249-53.

13. Nahar J, Zabeen B, Akhter S, Azad K, Nahar N. Neonatal morbidity and mortality pattern in the special care baby unit of Birdem. Ibrahim Med Coli J. 2007;1(2):1-4.

14. Gauchan E, Basnet S, Koirala DP, Rao KS. Clinical profile and outcome of babies admitted to neonatal intensive care unit (NICU). J Inst Med. 2011;33(2):1-8.

15. Ogunlesi TA, Ogunfowora Ob, Adekanmi AF, Feluga MB, Runsewe TI, Gundeyi MMO. Neonatal mortality at Olabisi Onabanjor University Teaching Hospital, Sagamu. Niger J Pediatr. 2006;33:40-6.

16. Hoque M, Haque M, Haaq S, Islam R. Causes of neonatal admission and deaths at a rural hospital in KwaZulu-Nall, South Africa. South Afr J Epidemiol Infect. 2011;26-9.

17. Seyal T, Husanain F, Anwar A. Audit of Neonatal morbidity and Mortality at Neonatal unit of Sir Gangaram Hospital Lahore. Annal King Edward Med Coll. 2011;1:913.

18. Butt NA, Malik A, Kazi MY. Pattern of neonatal admissions in tertiary care hospital. Pak J Med Health Sci. 2010;4:436-8.

19. Hoque M, Haque M, Haaq S, Islam R. Causes of neonatal admission and deaths at a rural hospital in KwaZulu-Nall, South Africa. South Afr J Epidemiol Infect. 2011;26-9.

20. Jan AZ, Ahmad S, Zahid AB. Clinical audit of admission pattern and its outcome in a neonatal ICU. Gomal $\mathrm{J}$ Med Sci. 2013;11:31-6.

21. Narayan R. A study of pattern of admission and outcome in a neonatal intensive care unit at high altitude. Sri Lanka J Child Health 2012;41:79-81. DOI:10.4038/ sljch.v41i2.4396.

22. Sharma P, Kaur P, Aggarwal A. Staphylococcus aureus- the predominant pathogen in the neonatal ICU of a tertiary care hospital in Amritsar, India. Clin Diagn Res. 2013;7(1):66-9. DOI:10.7860/jcdr/2012/4913.2672.

23. Shrestha S, Shrestha NC, Dongol Singh S, Shrestha RB, Kayestha S, Shrestha M, Thakur NK. Bacterial Isolates and its antibiotic susceptibility pattern in NICU. 2013;11(41):66 -70 .

24. Prakash J, Das N. Pattern of admission to neonatal unit. J Coli Physician Surg Pak. 2005;15:341-4.

25. Jamal M, Khan N. Neonatal morbidity and mortality in high risk pregnancies. J Coll Physician Surg Pak. 2002;12:657-61.
26. Jan AZ, Ahmad S, Zahid AB. Clinical audit of admission pattern and its outcome in a neonatal ICU. Gomal J Med Sci. 2013;11:31-6. 